\title{
Field-test of wind turbine by voltage source converter
}

\author{
Nicolás Espinoza and Ola Carlson \\ Department of Electrical Engineering, Chalmers University of Technology, Gothenburg, 412 96, Sweden \\ Correspondence: Ola Carlson (ola.carlson@chalmers.se)
}

Received: 25 April 2018 - Discussion started: 23 May 2018

Revised: 22 May 2019 - Accepted: 24 June 2019 - Published: 9 September 2019

\begin{abstract}
One of the main challenges for wind energy development is making wind turbines efficient in terms of costs whilst maintaining safe and reliable operation. An important design criterion is to fulfil the grid codes given by the transmission system operators. Grid codes state how wind farms must perform when connected to the grid under normal and abnormal conditions. In this regard, it is well-known that not all technical requirements can be tested by using actual impedance-based test equipment. Therefore, test equipment comprising a fully rated voltage source converter in back-to-back configuration is proposed. Thanks to the full controllability of the applied voltage in terms of magnitude, phase and frequency, the use of voltage-source-converter-based test equipment provides more flexibility compared to actual test systems. As demonstrated in this paper, the investigated test device not only can recreate any type of fault, including its recovery ramp, but also can carry out steady-state tests, such as frequency variations and frequency scan, on the test object. Finally, test results from a 4.1 MW wind turbine and 8 MW test equipment located in Gothenburg, Sweden, are shown to validate the investigated grid code test methodology.
\end{abstract}

\section{Introduction}

The reliability of the electrical grid depends on how well the generating units, including wind energy systems, are prepared to provide support in the case of grid contingencies. In this regard, transmission system operators (TSOs) have specific technical requirements included in their grid codes for connecting wind power plants into the electricity grid. In general terms, a grid code specifies how a generating plant should behave under normal and abnormal grid conditions. The continuous increase in electrical energy from wind power injected into the power system has led TSOs to impose ever more stringent requirements on these kinds of plants. It is therefore crucial to develop test methodologies for this type of technology to ensure correct integration of wind energy into electricity grids (Espinoza, 2016).

To evaluate the capability of wind turbines to withstand grid disturbances, tests are currently carried out on the generating unit by using an impedance-based voltage dip generator (Yang et al., 2012). By developing further new test methodologies, it will be possible to test for grid scenarios other than voltage dips, ensuring reliable and fault-tolerant opera- tion of the wind turbine system. Furthermore, in the future, wind turbines will be required to participate more actively in regulating the grid (Tsiliand and Papathanassiou, 2009). In this regard, it is well-known that voltage source converters (VSCs) can provide the necessary flexibility to control the terminal voltage as desired. On the other hand, electronic devices have become cheaper and more accessible over the years (Blaabjerg and Ma, 2013). It is therefore natural that future test devices will be partly or fully driven by VSC devices. For these reasons, a test run was carried out from January 2015 to August 2017 on a 4.1 MW full-power converter (FPC) wind turbine (also known as the "Big Glenn" wind turbine) using fully rated $8 \mathrm{MW}$ VSC-based test equipment.

\section{Review of grid code technical requirements}

The grid codes considered in this section refer to countries with high levels of wind power penetration into their national grids (EWEA, 2016). Consequently, these countries have developed detailed technical requirements for grid interconnection of wind power plants (Espinoza et al., 2013). 
The requirements for steady-state operation of the grid can be mainly categorised into three groups: reactive power requirements for normal voltage operation range, reactive power requirements during nominal active power production, and minimum operation time and active power curtailment during long-term frequency deviations. These requirements have been compared in Tsiliand and Papathanassiou (2009), Espinoza et al. (2013), Mohseni and Islam (2012), and Altın et al. (2010). A dedicated analysis of the German grid code is given in Erlich and Bachmann (2005). Finally, control strategies developed to meet grid code technical requirements have been documented in Bongiorno and Thiringer (2013), Molina et al. (2007), and Martinez and Navarro (2008).

\subsection{Requirements for steady-state condition of the grid}

A TSO can require reactive power injection from wind farms to support overall system voltage control during normal grid operation. Usually, reactive power requirements are delimited within a minimum power factor range from 0.95 lagging to 0.925 leading, an active power set point of between 0.05 and $1 \mathrm{pu}$, and within a nominal voltage varying between 0.9 and $1.1 \mathrm{pu}$.

Reactive power requirements are also dependent on the active power production of the wind farm. For instance, the Danish grid code (ENERGINET, 2010) stipulates dependencies between voltage and reactive power and between active and reactive power production. Both requirements must be complied with simultaneously during normal wind farm operation. Moreover, reactive power injection can be controlled, with either a voltage control or power factor control (Tsiliand and Papathanassiou, 2009). An additional option for defining reactive power production is to manually set the reactive power operating point if, for example, a continuous voltage deviation is present at the connection point.

Moreover, grid codes specify the steady-state frequency and voltage operation range within which the wind turbine should operate continuously. For voltages, normal condition is considered to be at $1.0 \mathrm{pu}$, with a frequency of 50 or $60 \mathrm{~Hz}$. A deviation of approximately \pm 0.1 pu from the rated voltage and $\pm 0.5 \mathrm{~Hz}$ from the rated frequency is also considered a normal condition. Any steady-state grid condition outside these boundaries is defined by a minimum operational time. In some cases, a control action on the active power set point of the wind farm can be requested by the TSOs: e.g. the Danish (ENERGINET, 2010), Irish (EirGrid, 2015) and German (E.ON, 2006, 2008) TSOs. When active power curtailment is requested in case of frequency deviations, the generation unit must vary its active power output in order to contribute to the overall regulation of the system frequency. In severe cases where the system frequency is outside the frequency operation band, the generating plant is allowed to disconnect.

\subsection{Requirements for dynamic condition of the grid}

Every grid code specifies a voltage dip profile that the wind turbine should ride through without tripping. An exhaustive comparison of low voltage ride through (LVRT) profiles is given in Tsiliand and Papathanassiou (2009), while LVRT profiles, characterised in terms of fault time, retained voltage and recovery ramp rates can be found in Mohseni and Islam (2012). Figure 1 shows a combination of the strictest LVRT profiles among the selected grid codes. In particular, the European grid code (ENTSO-E, 2016) defines the guidelines to establish the LVRT profiles in each network within the European Union (EU).

When specified in the grid code, wind parks are required to support voltage restoration by injecting reactive power into the grid. Specifically, the generating plant must provide voltage support by injecting a specific amount of reactive current depending of the retained voltage at the connection point. For example, the Danish grid code (ENERGINET, 2010) enforces a specific LVRT with a retained voltage of 0.2 pu per $500 \mathrm{~ms}$, as shown in Fig. 1, and stipulates reactive power support during voltage restoration. Reactive current must be injected in a linear fashion when the voltage deviates below $0.9 \mathrm{pu}$. When the system voltage is lower than $0.5 \mathrm{pu}$, nominal reactive current must be reached.

\subsection{Testing for grid code fulfilment}

The IEC 61400-21 standard issued by the International Electrotechnical Commission (IEC) defines the methodology for testing part of the technical requirement stipulated in grid codes, particularly for interconnecting wind turbines (IEC 61400-21 ed2.0, 2008). Moreover, specialised test equipment has been developed to fulfil the standard criteria (Yang et al., 2012).

The most common test device for LVRT testing of wind turbines is the impedance-based voltage dip generator (Beeckmann et al., 2010; Martinez and Navarro, 2008; Ausin et al., 2008). The impedances which constitute the test device are arranged to form a voltage divider at the terminals of the object being tested. By selecting the proper impedances, the amplitude and phase angle of the applied voltage can be controlled as desired. Although it has a simple and robust design which makes it modular and easily transportable, one of the main drawbacks of this test device is that it can only be applied to voltage step variations due to the closingopening action of the circuit breaker. Moreover, the device is highly dependent on the short-circuit power at the grid connection point, which will also impact the resulting wind turbine voltage (Ausin et al., 2008; Yang et al., 2012; Hu et al., 2009). Other devices have been developed in which the applicable voltage is controlled by VSC. For example, the test set-up presented in Saniter and Janning (2008) consists of a complex configuration of several VSCs and a three-winding transformer. The paper compares no-load tests and simula- 


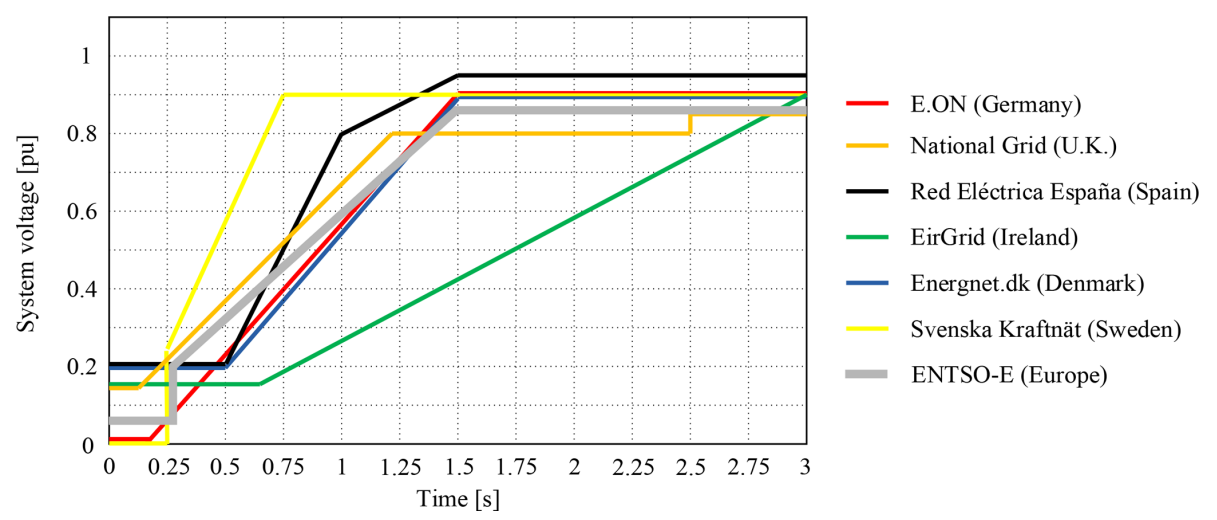

Figure 1. Example of LVRT profiles from the selected grid codes.

tion results, while the effectiveness of actual tests remains undisclosed.

A simple and flexible solution to realise a voltage dip generator is to use two fully rated VSCs in back-to-back configuration. By controlling the turbine-side output of the converter system, the effect of all kinds of grid faults can be emulated (Wessels et al., 2010). Thanks to the full controllability of the applied voltage in terms of magnitude, phase and frequency, the use of VSC-based test equipment, shown in Fig. 2, provides more flexibility compared to the standard impedancebased test equipment (Espinoza et al., 2013; Ausin et al., 2008). It also brings more advantages in terms of size and weight (Yang et al., 2012; Diaz and Cardenas, 2013). Furthermore, the AC grid is decoupled from the test object when conducting the test. This means that, if a proper control strategy is implemented for the grid-side VSC of the test equipment, grid strength is not a major limitation.

Moreover, the LVRT profile given in the majority of the grid codes can be fully tested, including the recovery ramp (Espinoza et al., 2013). Such precise control allows more test types to be conducted than normally required by grid codes. For example, frequency support capabilities of the test object can be evaluated by conducting a test in which the fundamental frequency applied at the point of common coupling (PCC) is varied. On the other hand, a frequency characterisation of the wind turbine can be conducted by introducing asynchronous frequency content into the applied voltage while observing the equivalence admittance at the PCC, as demonstrated later in this paper.

Since wind turbine data are not always available, the test equipment can be used to obtain more information from an actual wind turbine system (Espinoza, 2016). By using fully controllable VSC-based test equipment, it is possible to determine how well the wind turbine can reject frequency components other than the fundamental frequency. Thus, the generating unit can be scanned across a wider frequency range in which the wind turbine could interact with other elements already present in the interconnecting grid.
In this regard, frequency scan tests have been carried out using the test device to characterise the input admittance of the wind turbine unit being tested. In this paper, this analysis is limited to the sub-synchronous range. The implementation of the controller in the test equipment is discussed in Espinoza (2016).

The main drawback of this technology is that it is more expensive than the standard test device introduced in the previous section. In addition, the control algorithm needed to implement such an arrangement of VSC is more complex, while extra attention must be paid when dealing with over-currents due to the use of sensitive power electronics. Moreover, to emulate a grid fault as realistically as possible, the controller which computes the output voltage of the VSC needs to be of high dynamic performance (Lohde and Fuchs, 2009).

\section{Description of the test facility}

\subsection{System layout}

The test equipment is an $8 \mathrm{MW}$ back-to-back HVDC station located at the harbour in Gothenburg, Sweden (Göteborg Energi AB, 2019). Figure 3 displays the wind turbine itself. The turbine is located at the edge of the land and close to the sea. Most of the time, the wind turbine receives offshore wind from the northern part of Denmark. The station, shown in the upper right corner of Fig. 3, houses the interconnecting equipment shown at the bottom of the figure. A diagram of the wind turbine layout connected to the VSC-based test device, including the VSC, interconnecting filters and coupling transformer, is shown in Fig. 2.

\subsection{Description of the VSC-based test system}

The test equipment is rated at $8 \mathrm{MVA}$ at $10.5 \mathrm{kV}$. The wind turbine is coupled to the test device at the primary of the coupling transformer, as shown in Fig. 2. The secondary of the transformer is rated at $9.35 \mathrm{kV}$ and its impedance of $0.08 \mathrm{pu}$. A filter bank consisting of an inductance, a capacitor and one 


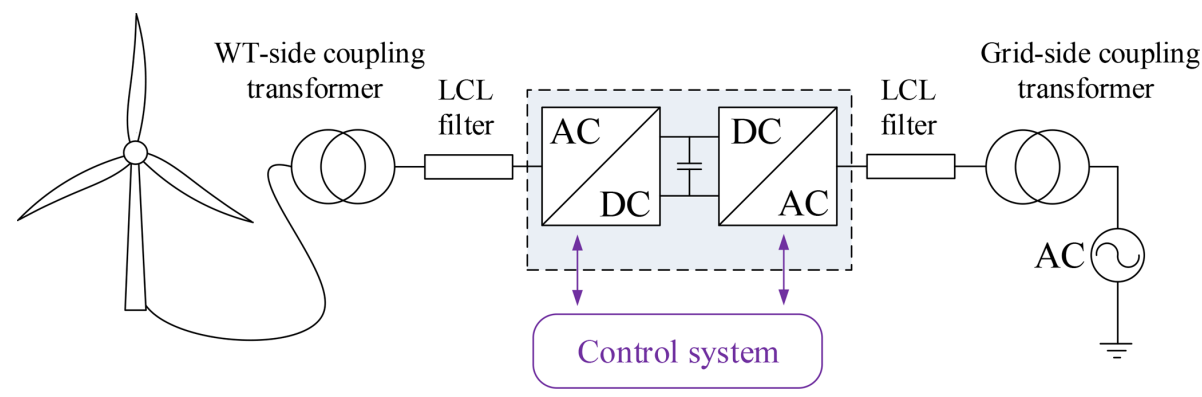

Figure 2. Single-line diagram of a VSC-based test equipment.
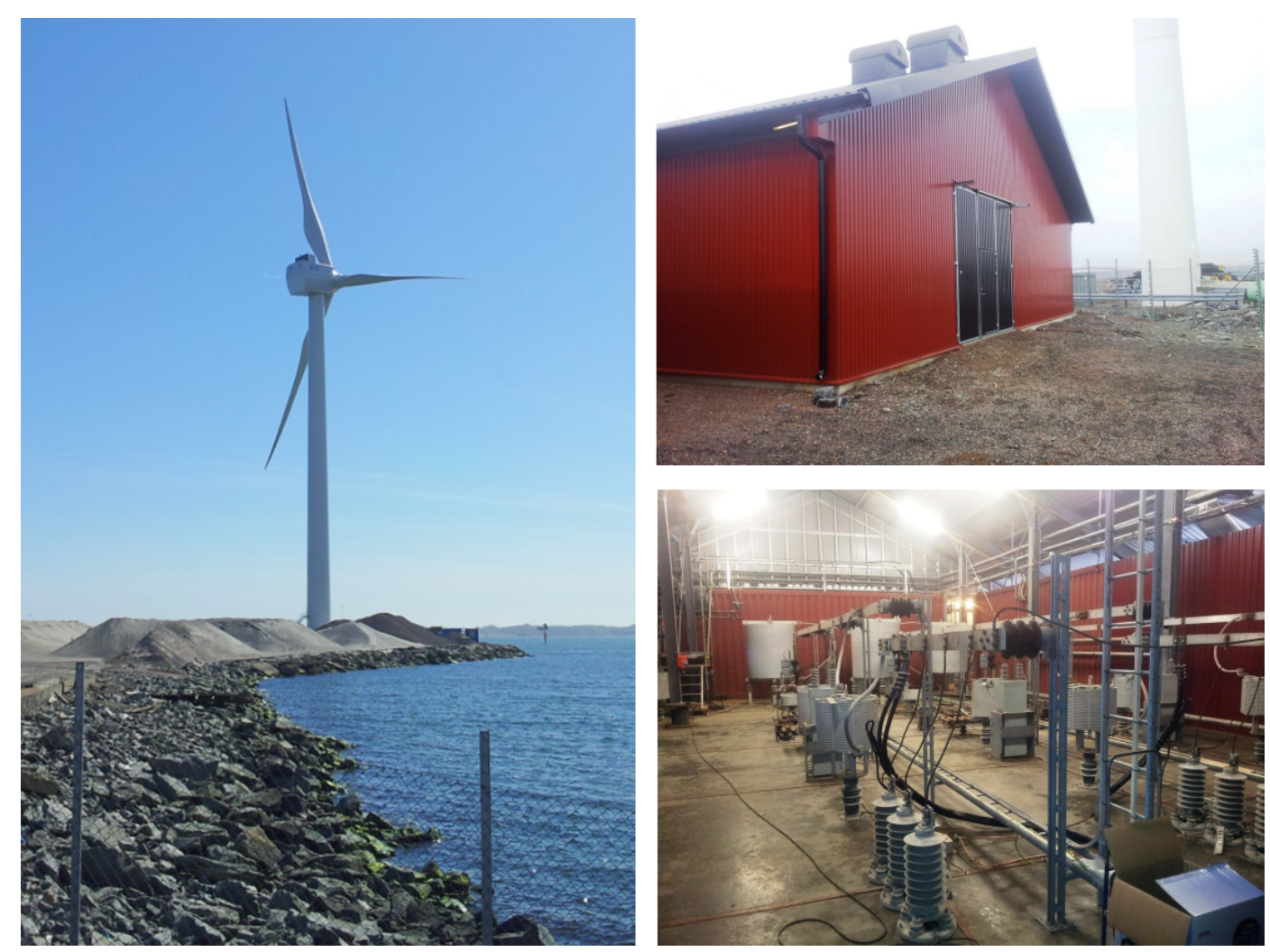

Figure 3. Gothenburg test facility, comprising the 4.1 MW FPC "Big Glenn" wind turbine. The facility houses the back-to-back HVDC station and coupling inductor (back) and AC filters (front).

more inductance (LCL) is placed to remove the harmonic content produced by the VSC itself. This converter controls the $\mathrm{AC}$ voltage imposed on the wind turbine system, while the grid-side converter controls the DC-link voltage by exchanging active power with the interconnecting grid. The test equipment is interfaced with the $10.5 \mathrm{kV}$ grid using again an LCL filter bank and coupling transformer. Finally, the wind turbine and test equipment are connected by a $300 \mathrm{~m}$ cable. In this installation, only the three-phase voltages and threephase currents at the PCC are sampled by a computer located in the HVDC station control room. The instantaneous active and reactive power are calculated offline.

\subsubsection{Control of the grid-side VSC}

The main blocks comprising the implemented discrete controller are the DC voltage control, inner current control, and pulse-width modulation (PWM) modulator block in cascade configuration and synchronised with the $\mathrm{AC}$ grid by means of a phase-locked loop (PLL). The outer DC voltage control generates the reference current for the inner current controller. The output of the current controller is the reference voltage at the terminals of the grid-side VSC. The output reference voltage is sent to a PWM block which computes the gating signal for the VSC transistors. The complete struc- 
ture of a typical controller for this type of application can be found in Espinoza (2016).

\subsubsection{Control of the turbine-side VSC}

A dedicated open-loop voltage control is incorporated in the control algorithm of the turbine-side VSC of the test equipment. The output of the controller is the reference value for the VSC terminal voltage. Finally, a PWM modulator is used to compute the switching signals of the converter (Espinoza, 2016).

\subsection{Big Glenn wind turbine}

In an FPC wind turbine, the generator is connected to the grid through a full-power rated back-to-back VSC, as shown in Fig. 4. A gearbox is typically used to step up the rotational speed when coupling the wind turbine hub with the generator shaft. In a direct-drive configuration similar to that found in Big Glenn (no gearbox in the drive train, allowing direct connection between hub and rotor), a dedicated lowspeed multi-pole generator must be used to achieve the desired nominal frequency in the stator terminals. The backto-back VSC is then used to transfer the generated power to the $\mathrm{AC}$ grid while allowing enough decoupling thanks to the DC link between the two VSCs in Fig. 4. This configuration allows for an increased fault-tolerant capability of the wind turbine, avoiding severe transients in the generator when a grid fault occurs. Moreover, the grid-side converter of an FPC wind turbine can be designed and controlled to provide additional reactive power support.

The use of fully rated back-to-back VSC for grid interconnection of wind turbine generators allows a fast response during abnormal grid conditions (Beeckmann et al., 2010; Perdana, 2014). For instance, during a voltage dip, generated power cannot be delivered into the grid due to insufficient grid voltage. In this scenario, the grid-side converter can quickly control the current output, avoiding the feeding of large-magnitude fault currents into the grid. The DC-link capacitor is protected by a DC crowbar. This allows redirection of the produced power into a resistor, providing fast DC over-voltage protection.

The wind turbine under test is rated at $4.1 \mathrm{MVA}$ at $10.5 \mathrm{kV}$. The stator of the generator, having a voltage rating of $0.69 \mathrm{kV}$, is directly connected to the back-to-back VSC. The generator-side VSC, here operated in torque control mode, injects the generated power into the wind turbine DC-link capacitor. The grid-side VSC controls the DC-link voltage by exchanging active power with the imposed AC grid. A filtering stage is placed between the VSC and the LV side of the wind turbine transformer in order to reduce the harmonic content injected into the electricity grid.

Finally, the output transformer of the wind turbine, with an impedance of $0.06 \mathrm{pu}$, steps up the voltage from 0.69 to $10.5 \mathrm{kV}$. Information about wind turbine control during faults can be found in Espinoza (2016), Perdana (2014) and Espinoza et al. (2015).

\section{Tests results}

\subsection{Testing for LVRT}

One of the first tests carried out on the test facility on 13 January 2015 corresponded to a voltage dip at full power production. The first attempt was to select a relatively small voltage variation, with a smooth transition between normal operation level and retained level. In order to conduct the experiment safely while learning the dynamics of the system, the voltage was reduced from 1 to $0.9 \mathrm{pu}$ for $100 \mathrm{~ms}$. The results are shown in Fig. 5. In the following and in all plots, a base voltage of $10.5 \mathrm{kV}$ and base power of $4.1 \mathrm{MVA}$ are used.

The three-phase PCC voltage is shown in Fig. 5. At $0.05 \mathrm{~s}$ the voltage is reduced from 1 to $0.9 \mathrm{pu}$. At $0.15 \mathrm{~s}$ the voltage is brought back to $1 \mathrm{pu}$. In this test, a stiff ramp rate of $0.2 \mathrm{pu} \mathrm{ms}^{-1}$ has been selected for the inception of the voltage dip, while a ramp of $0.01 \mathrm{pu} \mathrm{ms}^{-1}$ has been set for the recovery. In order to maintain constant power production during the voltage reduction, the generating unit increases the magnitude of the current while maintaining a constant power production, as also depicted in Fig. 5. During the voltage variation, the wind turbine maintains its active power set point, injecting a steady 0.9 pu of active power into the imposed grid. From the figure, it can be observed that the wind turbine does not engage its LVRT control. Thus, the reactive power is only reduced due to the reduction of the voltage across the $\mathrm{AC}$ link between the wind turbine and test equipment.

A second test was carried out the same day and during the time in which the wind turbine was still producing nominal active power. Here, the voltage was varied from 1 to $0.65 \mathrm{pu}$ for $100 \mathrm{~ms}$ with the same ramp rates as previously mentioned. In this test, the LVRT control strategy of the wind turbine was activated during the voltage dip, providing an indication of how sensitive fault ride-through thresholds are set in the test object. The results are presented in Fig. 6.

The three-phase PCC voltage is dropped at $0.05 \mathrm{~s}$. At $0.075 \mathrm{~s}$, it is possible to observe a transient in both the current and voltage shown in the figure. The transient lasts for $10 \mathrm{~ms}$ while the wind turbine manages to control its current output during the voltage dip. The wind turbine active power set point is maintained at $1 \mathrm{pu}$, while the reactive power is $0.2 \mathrm{pu}$ at pre-fault, reaching a mean value of $0.4 \mathrm{pu}$ during the voltage dip. The voltage starts its recovery at $0.18 \mathrm{~s}$ as per the ramp function. Note that the current is also reduced at the same time the reactive power is brought back to $0.2 \mathrm{pu}$. The active power oscillates at $0.23 \mathrm{~s}$ when the voltage has reached a steady-state level of $1 \mathrm{pu}$. Finally, observe that the current is above 1 pu during the voltage dip, meaning that the wind turbine has over-current capabilities and it is capable of momentarily increasing the output current beyond nominal values during the contingency. 


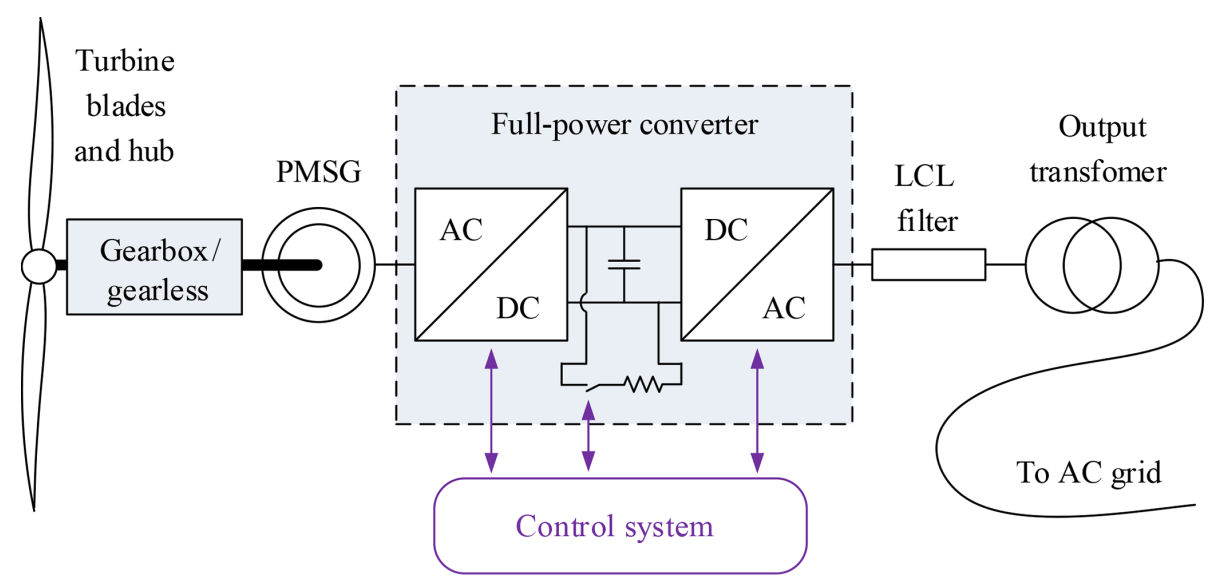

Figure 4. Schematic representation of an FPC wind turbine.
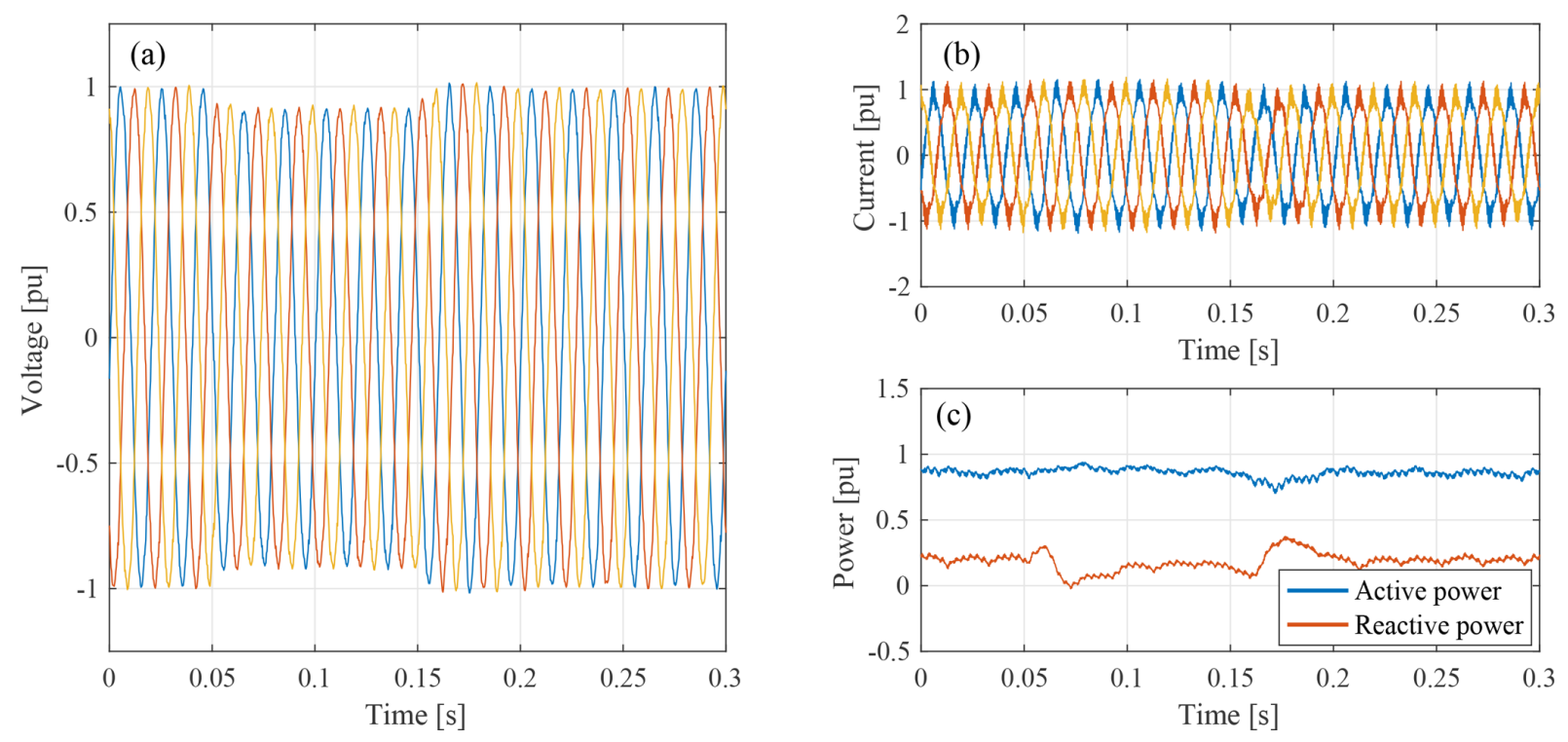

Figure 5. Wind turbine tested for voltage dip at full power production. The figure shows three-phase voltage (a) and current (b), plus active and reactive power output (c).

\subsection{Reactive power control during voltage dip}

A similar test was carried out on 17 May 2016. Unfortunately, the wind turbine was operating at low wind speed. However, the lack of active power produced made the variations in reactive power more prominent, as shown later in this section. This experiment consisted of a voltage variation from 1 pu to 0.75 for about $200 \mathrm{~ms}$. To avoid an oscillatory response similar to those experienced in the previous experiment, the down-slope ramp of the controlled VSC voltage was set at $0.04 \mathrm{pu} \mathrm{ms}^{-1}$ and recovery ramp at $0.0067 \mathrm{pu} \mathrm{ms}^{-1}$. From the voltage waveform given in Fig. 7, it is possible to observe that the voltage is controlled by the test equipment in an effective and smooth way. Moreover, due to reduced slope at dip inception the oscillatory response shown in Fig. 6 was not triggered.
The active power was set to 0.15 pu during this test. The reactive power seen in Fig. 7 at pre-fault is mainly due to the capacitor bank of the local LCL filter placed at the terminals of the turbine-side VSC of the test equipment, while the variation observed during the voltage dip is due to the control action of the wind turbine.

Note that the wind turbine injects reactive current when the voltage dip is detected at $0.12 \mathrm{~s}$. As shown in the figure, the current reached $1 \mathrm{pu}$, meaning that the turbine was operated at rated current. To quickly boost the voltage, the reactive power, also shown in Fig. 7, is increased using a ramp function. Reactive power injection is maintained for the complete duration of the voltage dip. The (mainly reactive) three-phase current is later reduced, once the voltage is restored to $1 \mathrm{pu}$. Note that the current is maintained briefly at $0.85 \mathrm{pu}$, while the voltage has already started to increase towards $1 \mathrm{pu}$. 

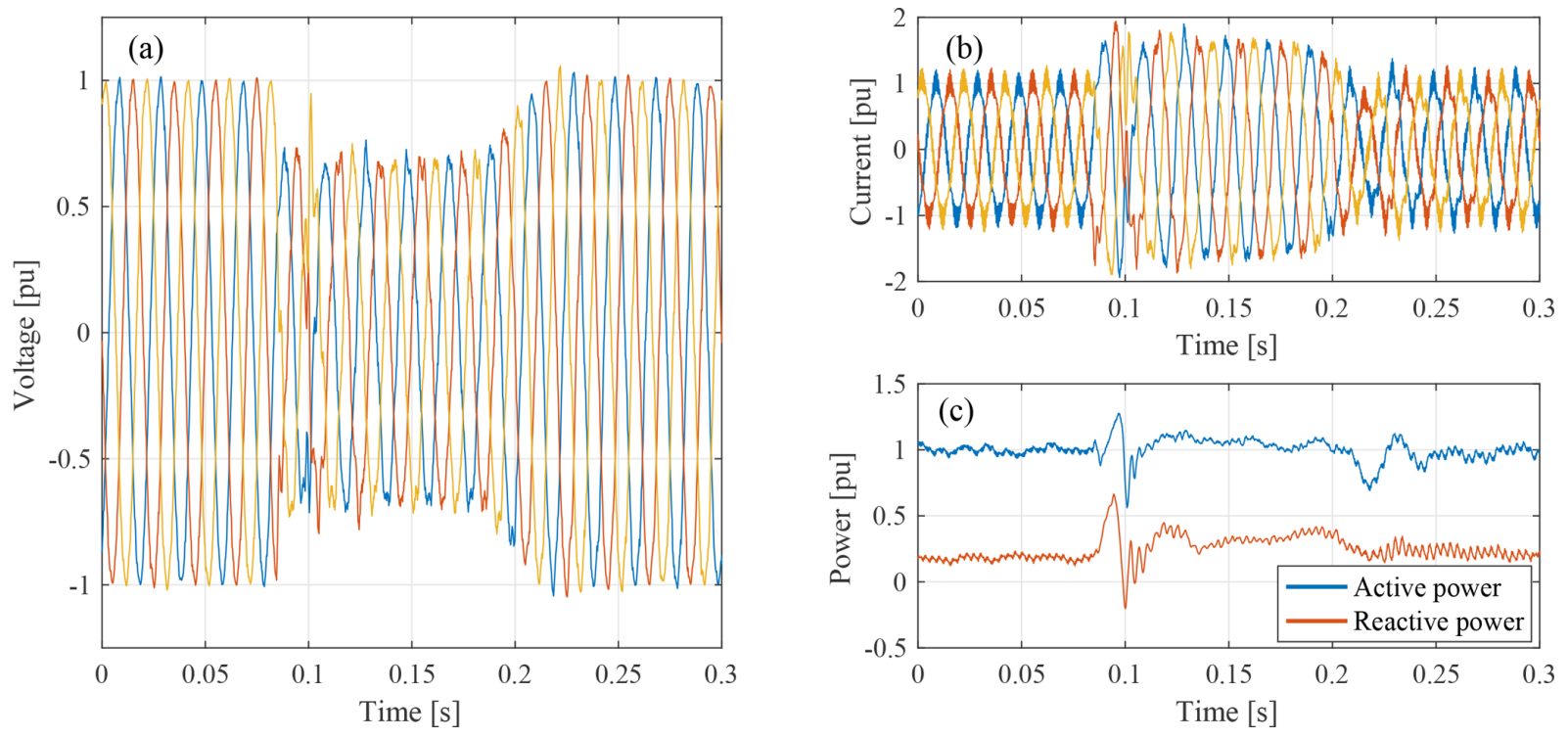

Figure 6. Wind turbine tested for LVRT at full power: three-phase voltage (a) and current (b), plus active and reactive power output (c).
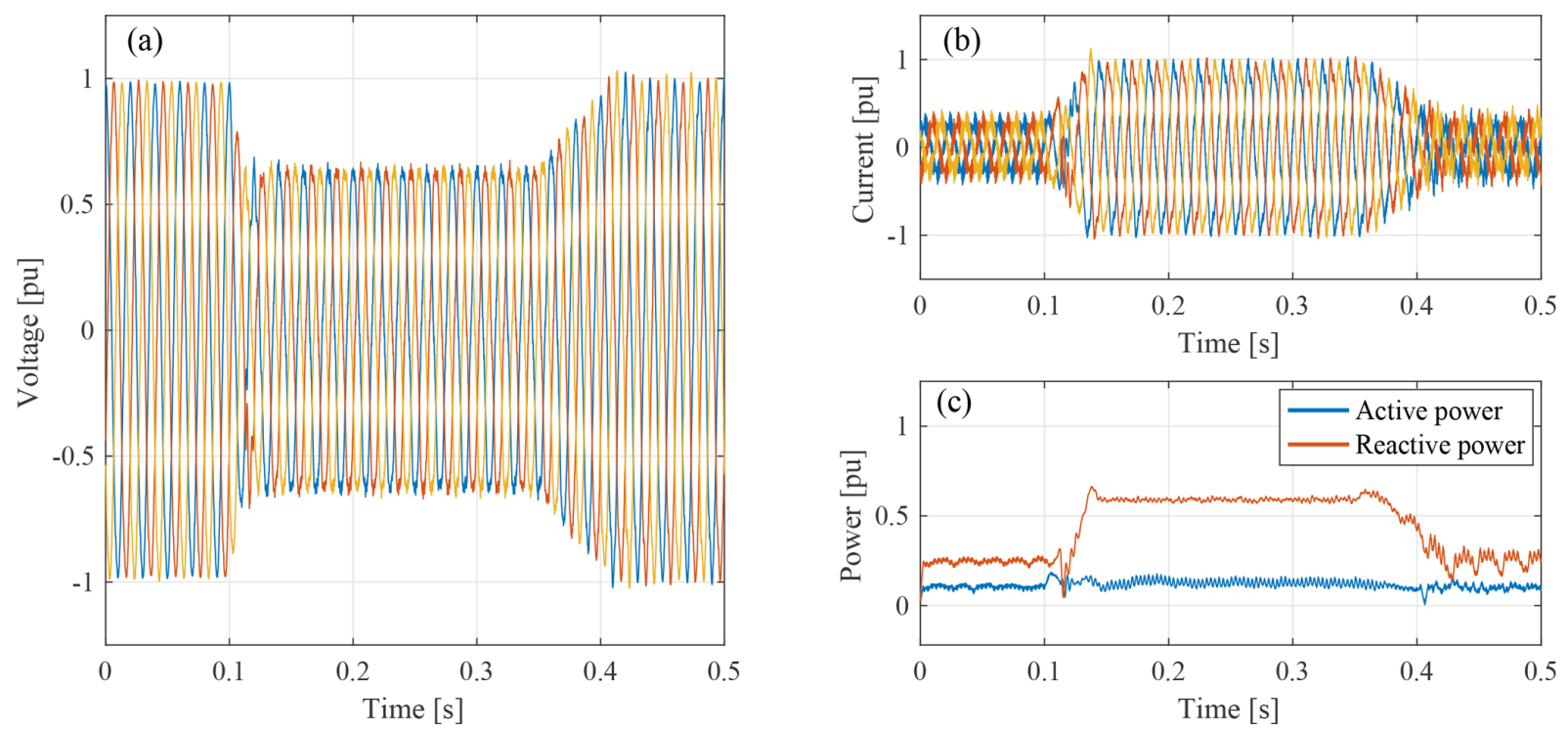

Figure 7. Wind turbine tested for LVRT at low power production: three-phase voltage (a) and current (b), and active and reactive power output (c).

A small transient on the reactive power set point can be observed both at fault inception and recovery. This can be attributed to the voltage monitoring system and the dynamics of the reactive power controller of the wind turbine - particularly to the wind turbine control action when calculating a reactive current reference based on a varying measured voltage. Afterwards, the wind turbine resumes normal operation, reducing the current (and therefore the reactive power output) to its pre-fault operating point. The system reaches a post-fault steady state at $0.43 \mathrm{~s}$.

\subsection{Testing for unbalance voltage dip}

This section studies the response of the wind turbine under unbalanced voltage dip. This test was conducted on 17 May 2016, under low wind conditions. Here, the turbineside VSC of the actual test equipment is controlled in an open loop, and the voltages in phases $\mathrm{a}$ and $\mathrm{b}$ are dropped from 1 to $0.7 \mathrm{pu}$ for $200 \mathrm{~ms}$. The resulting PCC voltage is given in Fig. 8. During the duration of the test, the voltage in phase $\mathrm{c}$ is maintained at $1 \mathrm{pu}$ from the VSC output. However, due the negative sequence across the $\mathrm{AC}$ circuit between test device and wind turbine, phase $\mathrm{c}$ appears slightly lower than $1 \mathrm{pu}$ at 

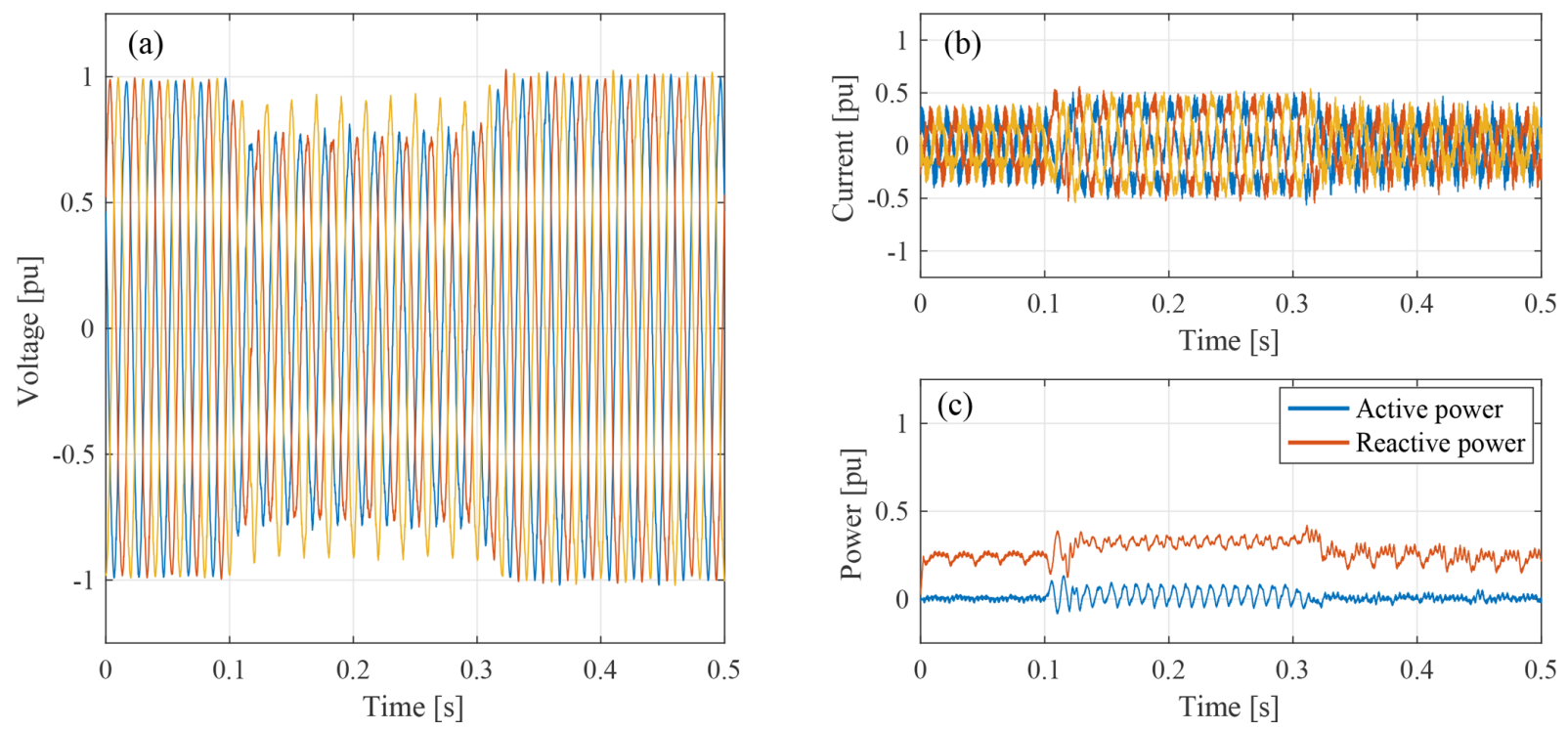

Figure 8. Wind turbine tested for unbalanced voltage dip at low power production: three-phase voltage (a), current (b) and active and reactive power output (c).

the measurement point. Moreover, observe from the power plot in Fig. 8 that the reactive power is increased from approximately 0.25 to $0.35 \mathrm{pu}$. A relatively small oscillation at $100 \mathrm{~Hz}$ in both active and reactive power is seen, mainly due to the small negative sequence present in the current.

These last three examples clearly illustrate the response of the wind turbine, particularly the reactive power controller during a balanced and unbalanced voltage dip. Given that the tested wind turbine's control system is unknown, these results suggest that the controller may also account for the negative sequence whilst still experiencing small oscillations in its output power.

\subsection{Impact of the voltage dip in wind turbine converter}

A voltage dip applied at the VSC terminals of the test equipment drastically affects the wind turbine converter voltage. Moreover, the grid-side VSC controller of the wind turbine will react to the voltage dip measured at the LV side of its step-up output transformer, particularly at the grid-side LCL filter shown in Fig. 4. Although the measured voltage will be somewhat smooth due to the wind turbine transformer impedance and filtering stage, the resulting output current and DC voltage of the back-to-back VSC are controlled in such way that the wind turbine can maintain normal operation when possible. In this regard, the internal signals of the grid-side wind turbine converter are plotted for the case in Fig. 6, and the effect of the voltage dip test is further discussed below.

If the voltage reduction does not dip sufficiently, the wind turbine might have some extra room in its rating to maintain normal power production at a reduced voltage (see Fig. 5). This can be done by increasing the current immediately after detecting a voltage dip. In this regard, Fig. 9 shows the effect of a voltage dip in the wind turbine converter. The voltage imposed is measured at $1 \mathrm{pu}$ and is dropped to $0.74 \mathrm{pu}$ for approximately $150 \mathrm{~ms}$. The VSC line current is also plotted in Fig. 9 and increases rapidly when the voltage dip is detected at $0.08 \mathrm{~s}$. Its pre-fault value is $0.85 \mathrm{pu}$ and rises to 1.3 pu during the dip.

The DC voltage (also shown in Fig. 9) is dropped during the test. This can be attributed to the rapid increase in wind turbine current, which can be faster than the time constant of the DC link capacitors at the wind turbine converter. This allows a normal power flow during the dip while slightly disturbing the DC voltage.

Finally, it is interesting to see the decoupling that exists between the grid-side VSC and the generator-side VSC of the wind turbine. Figure 10 shows the generator torque and speed when the grid voltage experiences a dip. If the conditions are met for the wind turbine VSC response to be smooth, the generator is unaffected. Here, the torque is maintained at a constant $1 \mathrm{pu}$ and the speed is also controlled at $1 \mathrm{pu}$. This means the wind turbine system is operated at full power. Note that the wind turbine converter has over-current capabilities to maintain a constant power flow during transients.

\subsection{Testing for frequency deviation}

In this case study, the voltage applied to the wind turbine is controlled at $1 \mathrm{pu}$, and only the fundamental frequency is varied. The results are shown in Fig. 11. To measure for a long time period, voltage and current are measured using a portable unit installed at the turbine side of the VSC-HVDC station. The unit is placed between the coupling transformer and the LCL filter shown in Fig. 3. For this reason, the re- 

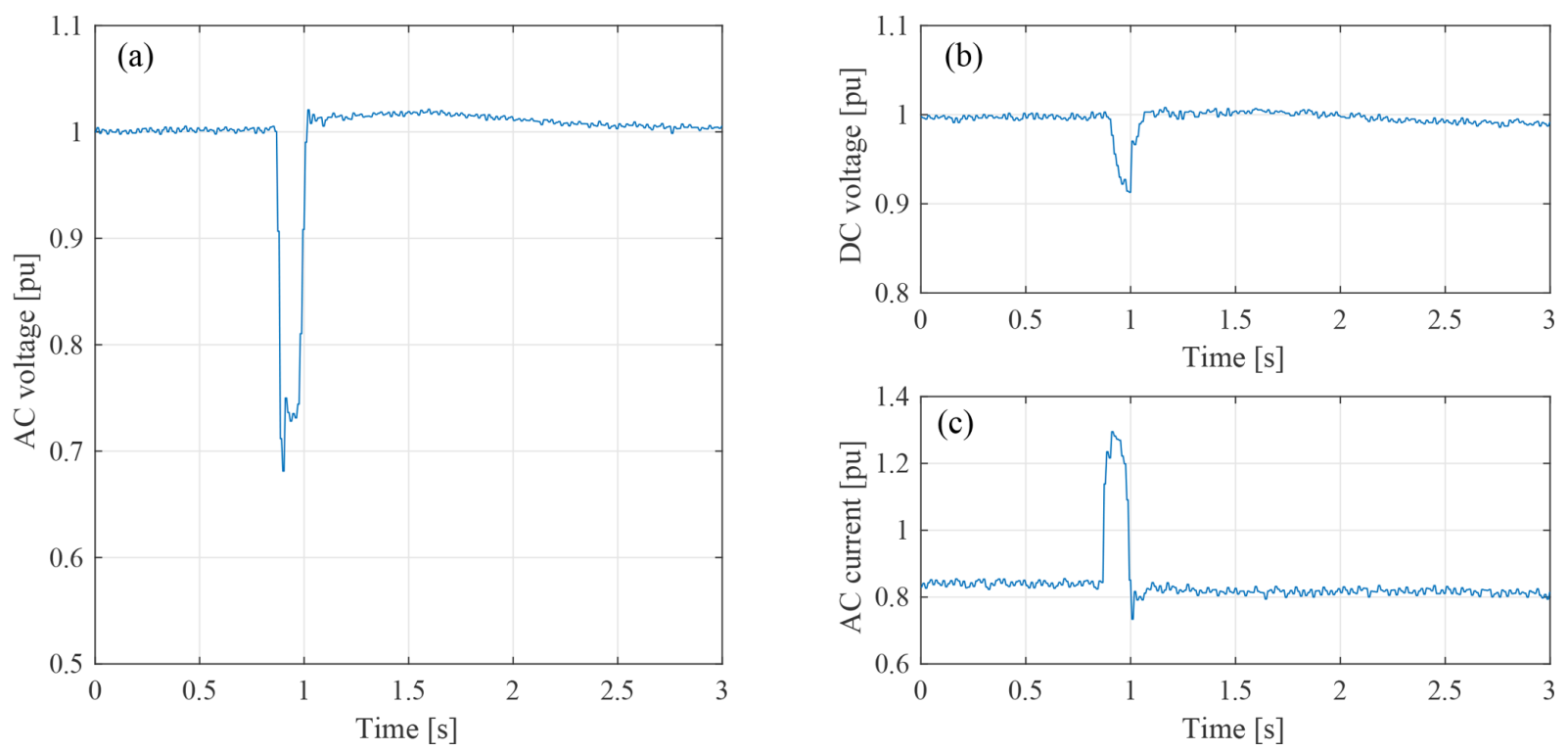

Figure 9. Wind turbine VSC under a voltage dip: AC voltage resulting at the LV side of the wind turbine transformer (a), and DC voltage (b) and AC current magnitude measured at the grid-side VSC (c).
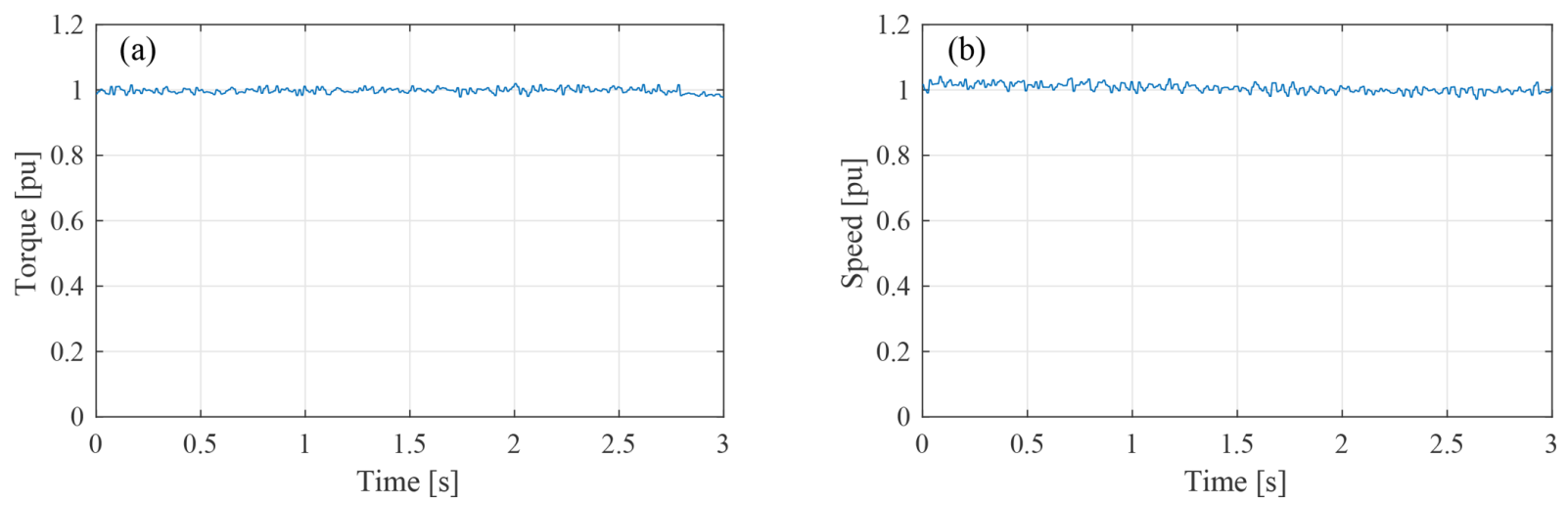

Figure 10. Wind turbine VSC under a voltage dip: generator torque (a) and speed (b).

active power curve (shown in red in Fig. 11) has a different value compared to the other case studies shown in this paper.

In the following, only the measured frequency and active and reactive power outputs are shown. The first scenario corresponds to a frequency drop of $0.5 \mathrm{~Hz}$ for $15 \mathrm{~s}$. From the first case shown in Fig. 11, it can be observed that the frequency varies with a ramp of $0.2 \mathrm{~Hz} \mathrm{~s}^{-1}$, or $5 \mathrm{~s}$ per varied $\mathrm{Hz}$, for both the drop and recovery of the frequency. According to the Swedish grid code (Svenska Kraftnät, 2005), the wind turbine should maintain its active power production at any given frequency within the specified normal frequency range (i.e. from 49.5 to $50.5 \mathrm{~Hz}$ ) while varying its output power for frequencies outside this range and ultimately ceasing to operate at frequencies outside the full operational range (i.e. 48 to $52 \mathrm{~Hz}$ ). The lower plot for frequency dip in Fig. 11 shows that the active power is kept constant at 0.7 pu for most of the time during the test. At $30 \mathrm{~s}$, the active power is slightly reduced, mainly due to variations in wind speed during the test.

The second scenario corresponds to two consecutive frequency swells of $1 \mathrm{~Hz}$. The frequency is initially controlled at $50 \mathrm{~Hz}$ and varied upwards with a ramp of $0.05 \mathrm{~Hz} \mathrm{~s}^{-1}$, or $20 \mathrm{~s}$ per varied $\mathrm{Hz}$. A frequency of $51 \mathrm{~Hz}$ is maintained for approximately $25 \mathrm{~s}$. The frequency is then increased to $52 \mathrm{~Hz}$. The results are shown on the right-hand side of Fig. 11.

Observe in the lower plot that the upward and downward tendency of the output power suggests that the wind turbine varies its operating point according to wind speed and not with demand for the applied frequency. In addition, the active power increases slightly $10 \mathrm{~s}$ after the frequency reaches $51 \mathrm{~Hz}$, at $40 \mathrm{~s}$ while continuing to increase as the system frequency increases, at $60 \mathrm{~s}$. A critical point is finally encountered at $80 \mathrm{~s}$ when the frequency reaches $52 \mathrm{~Hz}$. The wind turbine enters an operational mode which affects the active 

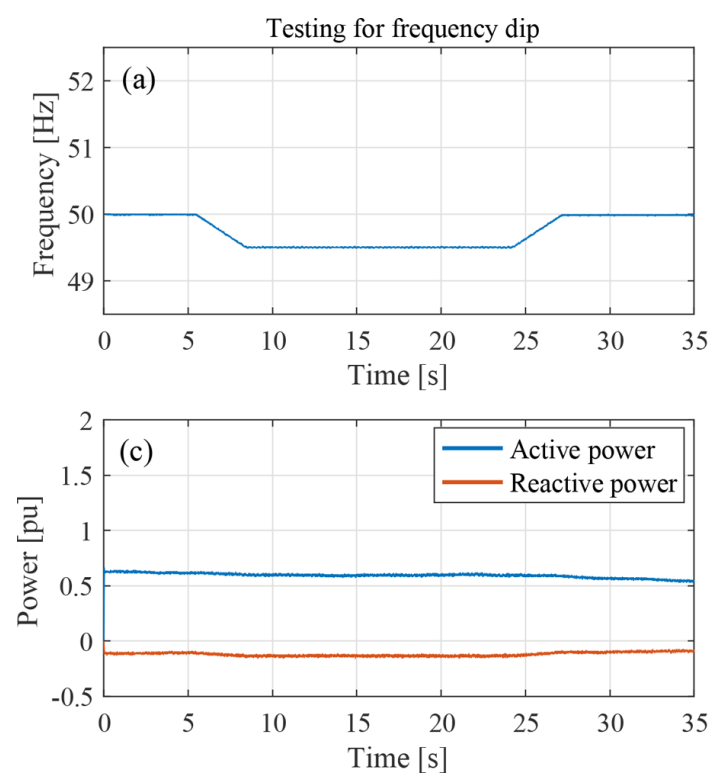
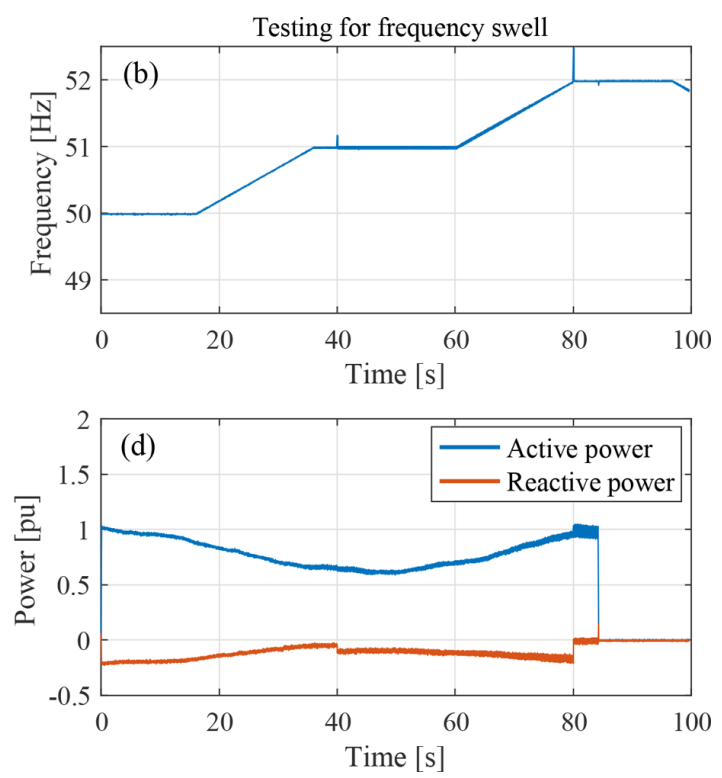

Figure 11. Frequency variation test, showing set points of active and reactive power during frequency dip (a, c) and frequency swell (b, d).

power output whilst experiencing an oscillation at roughly $100 \mathrm{~Hz}$. The wind turbine shuts down, via an over-frequency protection relay, $5 \mathrm{~s}$ after the frequency reaches $52 \mathrm{~Hz}$, at $t=85 \mathrm{~s}$. The different power production levels experienced when conducting the test are also somewhat reflected in the reactive power output of the wind turbine, as seen in the red traces for both scenarios in Fig. 11.

\subsection{Frequency scan}

Conducting a frequency scan on a wind turbine generator can provide valuable information about how the tested system behaves across a wider frequency range. This information is vital when analysing the risk of sub-synchronous oscillations, interaction with cables and filter banks or with active devices, such as Static Synchronous Condenser (STATCOM). The investigated method can also provide information for evaluating the stability and performance of large time-constant controllers, such as voltage control or power oscillation damping (POD) control installed in a wind energy system.

Firstly, this section shows the frequency scan test carried out on 20 June 2016, when the wind turbine was operating at $0.6 \mathrm{pu}$ power of production. Afterwards, the result of the frequency scan test carried out on 17 May 2016, at low power production, is given. The current and voltage are again measured at the HVDC station controlling the voltage applied to the wind turbine. The frequency scan is conducted by adding a voltage component of a magnitude of $0.015 \mathrm{pu}$ (modulated to the frequency being scanned) to the fundamental reference voltage of $1 \mathrm{pu}$. The measured phase voltage and line current are evaluated at the frequency of interest and using the methodology given in Espinoza (2016), also reported in Espinoza et al. (2016).
During the scan, the wind turbine changed its operating conditions during each tested frequency. The average power output of the wind turbine is measured at $2.9 \mathrm{MW}$. However, a wide variation between 2.6 and $3.5 \mathrm{MW}$ was encountered during the test, as shown in Fig. 12a as bars of different height. For each scan at a given frequency, the wind turbine impedance $Z_{\mathrm{w}}(j \omega)$ is obtained as an average of the phase impedances, while each phase impedance is computed with the corresponding voltage and current vector measured at the frequency of interest and averaged within the sampling period.

The wind turbine admittance $Y_{\mathrm{w}}(j \omega)$ can be calculated by the inverse of $Z_{\mathrm{w}}(j \omega)$. The real and imaginary parts, plus magnitude of the measured phase admittance $Y_{\mathrm{w}}(j \omega)$, are shown in Fig. 12b as blue and green diamonds respectively. The magnitude of the admittance is plotted as white diamonds. The resulting measured points in Fig. 12b suggest that the wind turbine presents a positive real part for frequencies below $22 \mathrm{~Hz}$, with a maximum measured value of $2.8 \mathrm{pu}$ at $10 \mathrm{~Hz}$. On the other hand, a relatively high non-passivity behaviour is seen for frequencies above $30 \mathrm{~Hz}$, meaning that the wind turbine could resonate if these frequencies are encountered in the network. The minimum value for $\operatorname{Re}\left(Y_{\mathrm{w}}(j \omega)\right)$ is $-1.5 \mathrm{pu}$ and can be observed at the last scanned frequency of $34 \mathrm{~Hz}$.

The scanned imaginary part of the admittance $\operatorname{Im}\left(Y_{\mathrm{w}}(j \omega)\right)$ is also shown in Fig. 12b as green diamonds. The turbine seems to exhibit capacitive behaviour for most of the studied frequency range. Note that the reactive power set point at the measurement point is dependent on both the configuration of the filtering stage at the VSC-HVDC terminals and on the wind turbine's reactive power controller. The minimum value of $\operatorname{Im}\left(Y_{\mathrm{w}}(j \omega)\right)$ is found to be $-2.4 \mathrm{pu}$ at $18 \mathrm{~Hz}$, ex- 

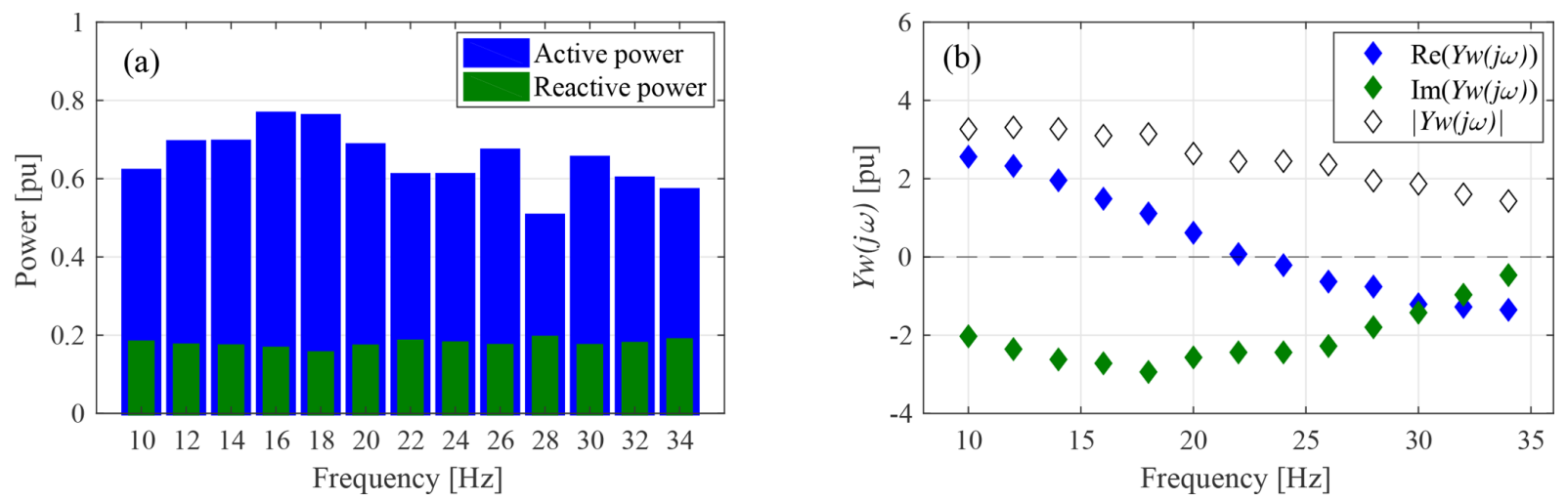

Figure 12. Results of frequency scan on the wind turbine operated at $65 \%$ of power production: operating points prior the scan and admittance components measured.
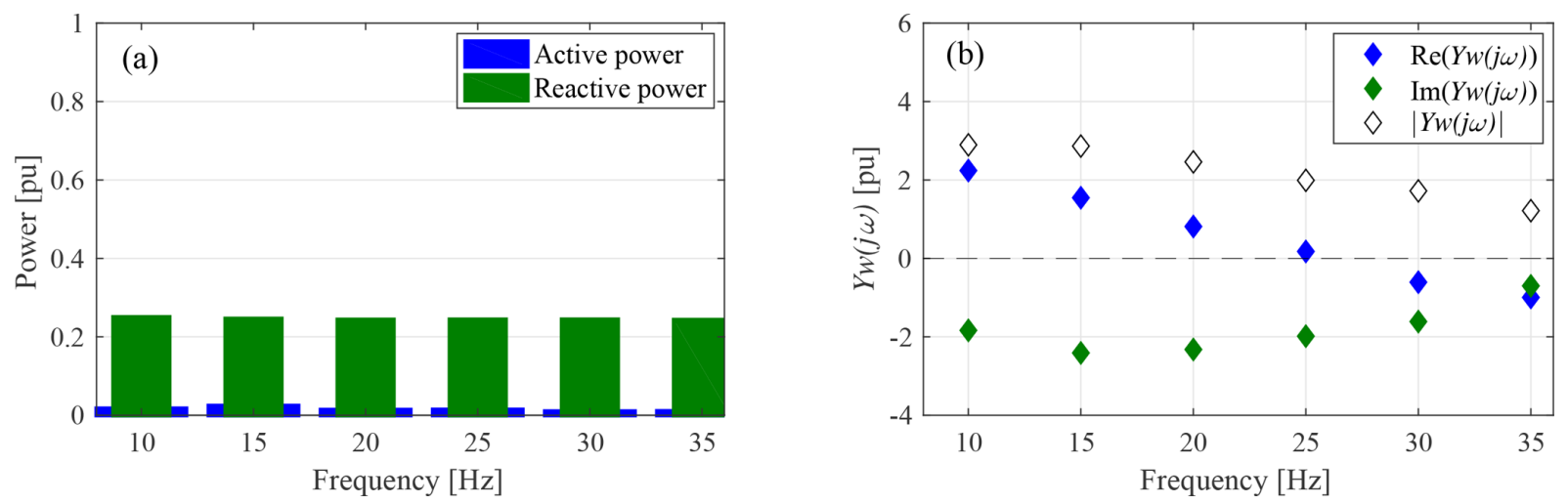

Figure 13. Results of frequency scan on wind turbine operated at $5 \%$ of power production: the operating points prior the scan and admittance components measured

hibiting its maximum capacitance in the scanned frequency range. For frequencies above $20 \mathrm{~Hz}, \operatorname{Im}\left(Y_{\mathrm{w}}(j \omega)\right)$ increases to a maximum of -0.4 pu measured at $34 \mathrm{~Hz}$, corresponding to its minimum capacitance in the sub-synchronous range. Observe, however, that the reactive power set point shown Fig. 12a is kept relatively constant at $0.2 \mathrm{pu}(0.9 \mathrm{MVAr})$ at $50 \mathrm{~Hz}$ throughout the test.

The absolute value of the measured wind turbine admittance $\left|Y_{\mathrm{w}}(j \omega)\right|$ is also shown in Fig. 12b as white diamonds. Note that the operating point of the wind turbine during each scan impacts not only the amplitude of the admittance but also its vector components. For this reason, the uneven trend of $\left|Y_{\mathrm{w}}(j \omega)\right|$ somewhat matches the variation on the output power of the wind turbine at each scanned frequency.

Finally, a second frequency scan is given in Fig. 13. The test was conducted on a day with very little wind; thus, the wind turbine was operating at low power production. The figure shows the active and reactive power set points at the moment of each test. Moreover, it can be noted that the power flow was dominated mainly by reactive power coming from the filter banks between wind turbine and test equipment, with a measured reactive power of 0.23 pu throughout the test. The calculated admittance magnitude and its real and imaginary components are also shown in Fig. 13 as white, blue and green diamonds, respectively.

The real component $\operatorname{Re}\left(Y_{\mathrm{w}}(j \omega)\right)$ shows a reduction of $0.3 \mathrm{pu}$ in its magnitude compared to the previous scan. However, the main difference is its zero-crossing, which in this case occurs at $26 \mathrm{~Hz}$, instead of $23 \mathrm{~Hz}$ for mid-power operation. From the plots where the reactive power is given, the second test shows a small increase in the reactive power measured at the HVDC station. Thus, $\operatorname{Im}\left(Y_{\mathrm{w}}(j \omega)\right)$ can be affected by the operating point of the wind turbine, making the green trace in Fig. 13 slightly closer to $0 \mathrm{pu}$, as compared with Fig. 12. Finally, $\left|Y_{\mathrm{w}}(j \omega)\right|$ is decreased from 4 pu in the first test to $2.7 \mathrm{pu}$ when operated at no power. Observe that the trend of $\left|Y_{\mathrm{w}}(j \omega)\right|$ is somewhat smoother given that the wind turbine operates at low power for the full duration of the scan. 


\section{Conclusions}

This paper has demonstrated that the full characterisation of the wind turbine system can be carried out by using flexible VSC-based test equipment. The full controllability of the test device allows for testing of multiple grid scenarios, making it possible not only to determine the behaviour of the generating unit against common grid contingencies, but also to evaluate the performance of the generating unit in further improving overall grid reliability. This includes evaluating different operating modes of the wind turbine, which can be of interest for the overall stability of the interconnected power system.

Field-test results from the Big Glenn 4.1 MW wind turbine and $8 \mathrm{MW}$ test equipment have been included in this paper. The tests carried out on the actual wind turbine system included not only balance and unbalanced voltage dips, defined by different retained voltage and different ramp rates, but also frequency variation tests and frequency scans. The results show that an LVRT control strategy is implemented in the tested system that injects reactive power when a voltage dip is detected. Moreover, it has been shown that the generating unit maintains smooth control of the reactive power output even during unbalanced voltage dips, at least for low power set points. These results demonstrate that a VSCbased test device can be used to evaluate how well a wind turbine system can withstand the technical requirements given in the grid codes.

The multi-megawatt FPC wind turbine system has also been characterised in the sub-synchronous range using the interconnected VSC-based test equipment. The frequency scanning technique has been demonstrated by field-tests, and the input admittance of the generating unit has been evaluated under two operating conditions. The frequency trend of the scanned turbine exhibits a non-passive behaviour at higher frequencies within the sub-synchronous range while also exhibiting capacitive behaviour throughout the complete scanned range.

The unique field-tests presented in this report have provided an experimental validation of the proposed wind turbine testing methodology, particularly on the wind turbine impedance characterisation and on the evaluation of its steady-state and dynamic performance under different grid conditions.

Data availability. Data presented in this work were obtained through several non-disclosure agreements. However, results can be obtained by contacting the authors.

Author contributions. OC organised the research with the $8 \mathrm{MW}$ test equipment. He also organised and took part in the measurements. NE prepared the manuscript, took part in the measurements, performed the data analysis and created the figures. OC provided guidance and comments.

Competing interests. The authors declare that they have no conflict of interest.

Acknowledgements. This work was carried out within the Swedish Wind Power Technology Centre (SWPTC). The set-up of the test equipment was done by Göteborg Energi with support from Protrol, among several companies. The tests were performed in collaboration with Protrol, Göteborg Energi and Chalmers University of Technology. The cooperation is greatly acknowledged.

Financial support. This research has been supported by the Swedish Energy Agency (grant no. 2014-002371, project no. 32591-2), the Västa Götelandsregionen (grant no. RUN 912-0969-14), and the Göteborg Energi AB (grant no. SN06: HVDC-lab).

Review statement. This paper was edited by Joachim Peinke and reviewed by two anonymous referees.

\section{References}

Altın, M., Göksu, O., Teodorescu, R., Rodriguez, P., Jensen, B. B., and Helle, L.: Overview of recent grid codes for wind power integration, in: 2010 12th International Conference on Optimization of Electrical and Electronic Equipment (OPTIM), 1152-1160, https://doi.org/10.1109/OPTIM.2010.5510521, 2010.

Ausin, J. C., Gevers, D. N., and Andresen, B.: Fault ride-through capability test unit for wind turbines, Wind Energy, 11, 3-12, https://doi.org/10.1002/we.255, 2008.

Beeckmann, A., Diedrichs, V., and Wachtel, S.: Evaluation of Wind Energy Converter Behavior during Network Faults - Limitations of Low Voltage Ride Through Test and Interpretation of the Test Results, in: 9th International Workshop on Large-Scale Integration of Wind Power into Power Systems as well as on Transmission Networks for Offshore Wind Power Plants, Jade Hochschule, 2010.

Blaabjerg, F. and Ma, K.: Future on Power Electronics for Wind Turbine Systems, IEEE J. Em. Sel. Top. P., 1, 139-152, https://doi.org/10.1109/JESTPE.2013.2275978, 2013.

Bongiorno, M. and Thiringer, T.: A Generic DFIG Model for Voltage Dip Ride-Through Analysis, IEEE T. Energy Conver., 28, 76-85, https://doi.org/10.1109/TEC.2012.2222885, 2013.

Diaz, M. and Cardenas, R.: Matrix converter based Voltage Sag Generator to test LVRT capability in renewable energy systems, in: 2013 8th International Conference and Exhibition on Ecological Vehicles and Renewable Energies (EVER), 1-7, https://doi.org/10.1109/EVER.2013.6521629, 2013.

EirGrid: EirGrid Grid Code Version 6.0, EirGrid, available at: http://www.eirgridgroup.com/site-files/library/EirGrid/ GridCodeVersion6.pdf (last access: 1 August 2019), 2015. 
ENERGINET: Technical regulation 3.2.5 for wind power plants with a power output greater than $11 \mathrm{~kW}$, https://en.energinet.dk/ -/media/BD322E7805694462AB125E5B5D0D79BC.PDF?la= en\&hash=DB619E3EAD98AD2F2691CEA0B68BE8B438F4B3FD (last access: 1 August 2019), 2010.

ENTSO-E: ENTSO-E Network Code for Requirements for Grid Connection Applicable to all Generators, available at: https:// www.entsoe.eu/network_codes/rfg/ (last access: 1 August 2019), 2016.

E.ON: Grid Code - High and Extra High Voltage, E.ON Nets $\mathrm{GmbH}$, Bayreuth, Germany, 2006.

E.ON: Requirements for Off-Shore Grid Connection in the E.On Nets Network, E.ON Nets GmbH, Bayreuth, Germany, 2008.

Erlich, I. and Bachmann, U.: Grid code requirements concerning connection and operation of wind turbines in Germany, in: IEEE Power Engineering Society General Meeting 2005, 2, 12531257, https://doi.org/10.1109/PES.2005.1489534, 2005.

Espinoza, N.: Wind Turbine Characterization by Voltage Source Converter Based Test Equipment, Doktorsavhandling PhD Thesis, Chalmers tekniska högskol, Ny serie, no: 4195, Department of Energy and Environment, Electric Power Engineering, Chalmers University of Technology, 2016.

Espinoza, N., Bongiorno, M., and Carlson, O.: Grid Code Testing of Full Power Converter Based Wind Turbine Using Back-to-Back Voltage Source Converter System, in: EWEA 2013 Annual Event Conference Proceedings, available at: http://publications.lib. chalmers.se/records/fulltext/174669/local_174669.pdf (last access: 1 August 2018), 2013.

Espinoza, N., Bongiorno, M., and Carlson, O.: Novel LVRT Testing Method for Wind Turbines Using Flexible VSC Technology, IEEE T. Sustain. Energ., 6, 1140-1149, https://doi.org/10.1109/TSTE.2015.2427392, 2015.

Espinoza, N., Bongiorno, M., and Carlson, O.: Frequency characterization of type-IV wind turbine systems, in: 2016 IEEE Energy Conversion Congress and Exposition (ECCE), 1-8, https://doi.org/10.1109/ECCE.2016.7855126, 2016.

EWEA: Wind in Power, 2015 European statistics, The European Wind Energy Association, available at: https://www.ewea.org/fileadmin/files/library/publications/ statistics/EWEA-Annual-Statistics-2015.pdf (last access: 1 August 2019), 2016.

Göteborg Energi AB: Göteborg Wind Lab, available at: http://www. goteborgwindlab.se (last access: 26 June 2017), 2019.

$\mathrm{Hu}, \mathrm{S}$., Li, J., and $\mathrm{Xu}, \mathrm{H} .:$ Comparison of Voltage Sag Generators for Wind Power System, in: APPEEC 2009, AsiaPacific Power and Energy Engineering Conference 2009, 1-4, https://doi.org/10.1109/APPEEC.2009.4918228, 2009.
IEC 61400-21 ed2.0: Wind turbines - Part 21: Measurement and assessment of power quality characteristics of grid connected wind turbines, International Electrotechnical Commission, Germany, 2008.

Lohde, R. and Fuchs, F.: Laboratory type PWM grid emulator for generating disturbed voltages for testing grid connected devices, in: 13th European Conference on Power Electronics and Applications 2009 (EPE'09), 1-9, 2009.

Martinez, I. and Navarro, D.: Gamesa DAC converter: the way for REE grid code certification, in: 13th Power Electronics and Motion Control Conference 2008 (EPE-PEMC 2008), 437-443, https://doi.org/10.1109/EPEPEMC.2008.4635305, 2008.

Mohseni, M. and Islam, S. M.: Review of international grid codes for wind power integration: Diversity, technology and a case for global standard, Renew. Sustain. Energ. Rev., 16, 3876-3890, https://doi.org/10.1016/j.rser.2012.03.039, 2012.

Molina, M., Suul, J. A., and Undeland, T.: A Simple Method for Analytical Evaluation of LVRT in Wind Energy for Induction Generators with STATCOM or SVC, in: 2007 European Conference on Power Electronics and Applications, 1-10, https://doi.org/10.1109/EPE.2007.4417780, 2007.

Perdana, A.: Dynamic Models of Wind Turbines, Chalmers University of Technology, Gothenburg, Sweden, available at: http: //www.chalmers.se/ (last access: 26 June 2017), 2014.

Saniter, C. and Janning, J.: Test Bench for Grid Code Simulations for Multi-MW Wind Turbines, Design and Control, IEEE Transactions on Power Electronics, 23, 1707-1715, https://doi.org/10.1109/TPEL.2008.925425, 2008.

Svenska Kraftnät: The Business Agency Svenska kraftnats regulations and general advice concerning the reliable design of production plants, Svenska Kraftnat, 2005.

Tsiliand, M. and Papathanassiou, S.: A review of grid code technical requirements for wind farms, in: IET Renewable Power Generation, 3, 308-332, https://doi.org/10.1049/iet-rpg.2008.0070, 2009.

Wessels, C., Lohde, R., and Fuchs, F.: Transformer based voltage sag generator to perform LVRT and HVRT tests in the laboratory, in: 2010 14th International Power Electronics and Motion Control Conference (EPE/PEMC), Ohrid, Macedonia, 6-8 September 2010, https://doi.org/10.1109/EPEPEMC.2010.5606830, 2010.

Yang, Y., Blaabjerg, F., and Zou, Z.: Benchmarking of Voltage Sag Generators, in: IECON 2012 - 38th Annual Conference on IEEE Industrial Electronics Society, 943-948, https://doi.org/10.1109/IECON.2012.6389164, 2012. 